Lichenologist, $10: 47-67$ (1978)

\title{
THE ASCUS APEX IN LICHENIZED FUNGI I. THE LECANORA-, PELTIGERA- AND TELOSCHISTES-TYPES
}

\author{
R. HONEGGER *
}

\section{Introduction}

The structure and method of discharge of the asci and the ascocarp ontogeny form the base of a natural classification of the Ascomycotina. The structure and method of discharge of asci in the ascohymenial Lecanorales is particularly poorly understood, some authors terming these unitunicate (Luttrell, 1951; Müller and Löffler, 1968; Richardson, 1970), and others bitunicate (Korf, 1958; Kreisel, 1969). The introduction of special terms for lichen asci, such as 'infissituniqué $v s$. fissituniqué' (Dughi, 1957) or 'bituniqué-archaeascé' (Chadefaud et al., 1963, etc.; LetrouitGalinou, 1973) may indicate both difficulties in correlating structures observed in lecanoralean asci with those found in non-lichenized Ascomycotina, and lichenologists sometimes failing to correlate their terminology with that generally used by other mycologists.

It is important to appreciate that the terms unitunicate and bitunicate were introduced by Luttrell (1951) as functional ones, relative to the behaviour of the ascus wall and the apical apparatus during dehiscence and spore discharge. Luttrell pointed out that the ascus wall of an unitunicate ascus 'may be laminated in structure', but the different layers never separate during dehiscence. Some authors now believe that the ascus wall in general, and that of the Lecanorales in particular, is two- or even multilayered. On this basis the term unitunicate has been rejected for the Lecanorales; Dughi (1957) replaced it by 'infissituniqué', while Chadefaud and his co-workers have introduced the 'type bituniqué-archaeascé' which they regard as a third main ascus type additional to the two distinguished by Luttrell. As Luttrell's definitions are generally accepted by mycologists, it appears confusing to have a multilayered but functionally unitunicate ascus treated as a variant of the bitunicate type.

The 'type bituniqué-archaeascé' is considered by Chadefaud's school to be the most archaic amongst the extant Ascomycotina (Chadefaud, 1973). LetrouitGalinou (1973: 32, transl.) defines the 'type bituniqué-archaeascé' as: 'Wall and dome thick and amyloid, generally with annular structures, with an apical nasse, and a specialized mode of dehiscence'. An archaic type would be expected to have developed in different ways and Letrouit-Galinou (1973) distinguished three phylogenetic stages in this ascus type: (1) 'pré-archaeasce' with three-layered walls in which the innermost ('endoascus interne') forms the apical dome (Fig. la) and

* Institut für Pflanzenbiologie/Cytologie der Universität Zürich, Zollikerstrasse 107, CH-8008 Zürich, Switzerland. 
where dehiscence occurs by a longitudinal split; (2) 'eu-archaeascé', the most widely distributed type in the Lecanorales, where the 'endoascus interne' is completely reduced in the basal and lateral parts of the ascus, but still forms a thick, amyloid dome which becomes elongated into a beak during dehiscence (Fig. 1b); and (3) 'post-archaeascé', linking the 'bituniqué-archaeascé' and the 'annellascé' types. The 'type annellascé' is found in pyrenomycetes and characterized by its eversible apical ring (Greenhalgh and Evans, 1967; Reeves, 1971; Beckett and Crawford, 1973; Griffiths, 1973; Hohl and Streit, 1975).

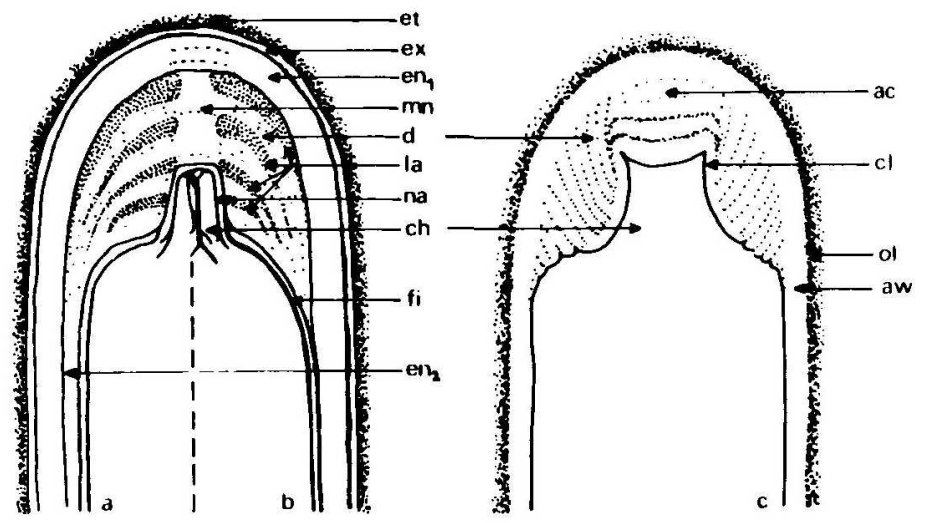

FIG. 1. Diagrammatic interpretations of the Lecanora-type ascus apex. (a) 'Type préarchaeascé' and (b) 'type eu-archaeascé' according to Letrouit-Galinou (1973). (c) According to TEM studies of Physcia stellaris.

ch, chambre oculaire; $\mathrm{en}_{1}$, endoascus externe; $\mathrm{en}_{2}$, endoascus interne; et, gélin amyloide; ex, exoascus; fi, film interne; la, lamelles amyloides; mn, manubrium; na, nasse apicale. ac, apical cushion; aw, ascus wall; ch, ocular chamber; cl, central layer; d, dome; ol, outer layer of ascus wall.

According to Letrouit-Galinou (1973), the 'type bituniqué-archaeascé' can be distinguished from the 'type bituniqué-nassascé' (which corresponds to the bitunicate type sensu Luttrell, 1951) by the position of the gliding sites during dehiscence. In the 'type bituniqué-archaeascé' the gliding site is found between the 'inner and outer endoascus', whereas in the 'type bitnuniqué-nassascé' gliding occurs between the 'exoascus and the outer endoascus'.

Unfortunately, most mycologists and lichenologists have found the structures described by the French specialists very difficult to observe. As many of the structures mentioned are at the limits of resolution of light microscopy (LM), transmission electron microscope (TEM) studies are needed. Only one previous paper has described the fine structure of a lecanoralean ascus using TEM (Rudolph and Giesy, 1968). In the present study a member of each phylogenetic stage of the 'type bituniqué-archaeascé' proposed by Letrouit-Galinou (1973) has been investigated by both LM and TEM. The 'type pré-archaeasce' was studied in Xanthoria parietina (Teloschistes-type), the 'type eu-archaeascé' in Physcia stellaris (Lecanora-type), and the 'type post-archaeascé' in Peltigera canina (Peltigera-type). 


\section{Light microscopy}

\section{Materials and Methods}

For LM studies the material was prepared according to the methods of Letrouit-Galinou (1973), but without treatment with potassium hydroxide prior to staining. Lactophenolcottonblue and Lugol's solution were most frequently used as stains, but Janus green, Waterman's ink and ammoniacal congo red were also occasionally employed.

\section{Electron microscopy}

For TEM investigations freshly collected material was fixed in (a) $1 \%$ potassium permanganate in water for $45 \mathrm{~min}$ at room temperature, and (b) $2 \%$ glutaraldehyde and $1.5 \%$ acrolein in Soerensen's phosphate buffer $(1 / 15 \mathrm{M}, \mathrm{pH} 7.0)$ at room temperature for $2 \mathrm{~h}$ and then $2 \%$ osmium tetroxide overnight. Both (a) and (b) were dehydrated in acetone and embedded in Spurr's low viscosity medium (standard mixture). Sectioning was carried out on a Reichert ultramicrotome with a Dehmer diamond knife, and the sections stained with uranyl acetate and Reynold's lead citrate. The sections were examined in either a Zeiss EM 9 or a Hitachi HS 8 electron microscope.

The material most suited to TEM investigations was found to occur in winter. At this time humidity (snow, rain, mist and little evaporation due to low temperatures) was sufficiently high to keep the hymenia more or less saturated with water for several weeks. In the samples collected in winter all stages of ascus and ascospore development were observed. Material collected in summer or after a period of drought, in contrast, proved to be unfavourable as it contained either very young or old degenerate asci.

\section{Results \\ Lecanora-type \\ (Corresponding to the 'type eu-archaeascé' of Letrouit-Galinou, 1973)}

Light microscopic studies of the Lecanora-type have been published by Ziegenspeck (1926), Magne (1946), Chadefaud et al. (1963, 1969), Letrouit-Galinou (1970, 1973) and Richardson (1970). All these authors observed a conspicuous amyloid dome at the ascus apex and dehiscence with a rostrum. Rudolph and Giesy (1968) were the first and so far the only workers to make a TEM investigation of a lecanoralean ascus. They observed that in the ascus apex of Physcia aipolia there was an apical thickening consisting of an electron-transparent matrix with electron-dense inclusions. As median sections are lacking in this TEM study the function of the apical thickening was not appreciated. In the present study the ascus apex of Physcia stellaris was investigated.

\section{Light microscopy}

The nonamyloid ascus wall is surrounded by an amyloid outer layer which passes into the hymenial gelatine from which it is not sharply delimited. In the apex of the premeiotic ascus the amyloid dome develops inside the nonamyloid ascus wall. In the central part of the dome a nonamyloid zone is observed which seems to correspond to the 'coussinet apical' and the 'manubrium' described by Chadefaud et al. (1963, etc.). As there was no 'mouth-like' zone (manubrium) visible the whole non-amyloid central part of the dome is termed the apical cushion here (Plate $1 \mathrm{D}(\mathrm{i})$ ). In a very few cases a structure looking like an apical nasse was seen; this occurred exclusively in pre-meiotic asci. During dehiscence the ascus wall bursts at the apex, and thereafter the amyloid material of the dome becomes elongated into a rostrum which reaches the hymenial surface [Plate $1 \mathrm{D}$ (iv)-(vi)]. 

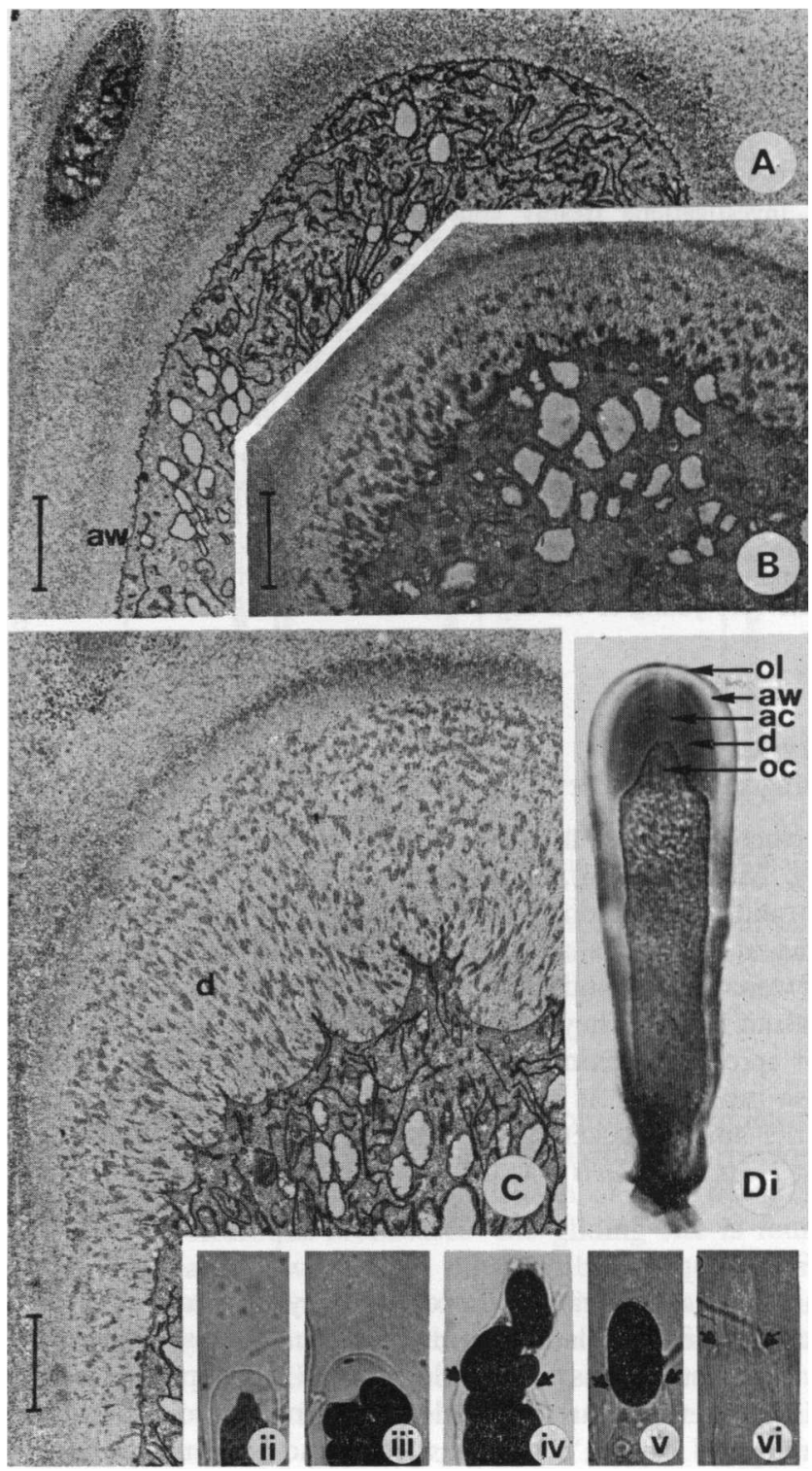

Plate 1. Physcia stellaris. A, Median longitudinal section of a young, still growing, ascus. $B, C, A s c u s$ at the onset of dome formation. The fusion of vesicles with the plasma membrane can be seen in B; fixation in potassium permanganate. $D, L M$ observations; (i) after staining with Lugol's solution; (ii)-(vi), after staining with lactophenol-cottonblue.

The scale indicates $1 \mu \mathrm{m}$ in all plates. 
The uppermost ascospores first remain enclosed in this rostrum, but then, probably after imbibition, the rostrum ruptures at its tip and the ascospores are released, normally simultaneously.

\section{Electron microscopy}

In young asci which are still growing, the ascus wall is, as in growing vegetative hyphae, thinner at the apex than in the lateral parts (Plate 1A); after reaching its mature size, however, it assumes a uniform thickness over the whole ascus. The ascus wall is surrounded by an outer layer ('fuzzy coat') identical to the amyloid coat observed in LM. Inside the ascus wall an amyloid dome is formed (Plate 1B-C); this consists, as described by Rudolph and Giesy (1968), of an electron-transparent matrix with granular electron-dense inclusions. These inclusions seem to be responsible for the positive reaction of the dome to iodine. In longitudinal and cross-sections the cytoplasm in the region of the ocular chamber can be seen to be intensely branched during the formation of the dome (Plate 2A-D). The branching is very irregular and the branching pattern varies from one ascus to another within the same hymenium. The 'nasse apicale-effect' described by Chadefaud and his co-workers is probably made up of these cytoplasmic branchings. In the mature ascus of Physcia stellaris the branchings have more or less disappeared. In the nearly complete dome an innermost layer lacking the electron-dense inclusions is deposited around the ocular chamber (Plate 2B, D); this central layer seems to play an important rôle during dehiscence.

The formation of the dome is completed just prior to the onset of meiosis. During ascospore maturation, the structure, and possibly also the chemical composition, of the central part of the dome (corresponding to the apical cushion observed in LM) change slightly, probably with regard to dehiscence and spore discharge. In this zone the granular electron-dense inclusions disappear (Plate 3A) and in their place a fine, lamellate structure becomes apparent (Plate 3B). Prior to dehiscence the uppermost ascospore becomes pressed into the ocular chamber (Plate 4A). Consequently, the material of the dome is intensely compressed and the apical ascus wall and the apical cushion rupture; the central layer, however, remains intact. The material of the dome, being fixed both at the lateral ascus wall and at the central layer, is then vigorously stretched by the ascospores entering the enlarged ocular chamber. In this way the rostrum reaching the hymenial surface is formed (Fig. 2). There are no gliding sites between different layers of the ascus wall.

The degeneration and reduction of the ascus and enclosed ascospores is of some interest. In Physcia, as well as in other Lecanorales, it can be observed that during a drought period the asci do not manage to release their spores. Some of the spores may begin to germinate in the ascus, as has been described by Rudolph and Giesy (1968), but then both the germinated and ungerminated spores shrink and degenerate. The apical dome of the ascus first shows a lamellate structure (Plate 4C) due to a confluence of the granular electron-dense inclusions. These lamellae stain intensely blue with iodine and therefore are readily visible in LM. This phenomenon was described by Chadefaud and his co-workers as the "delamination du dôme' and interpreted as a characteristic component of the lecanoralean ascus but TEM studies clearly show that the occurrence of these lamellae merely marks the onset of ascus degeneration. The lamellae seem to be of no importance in the 

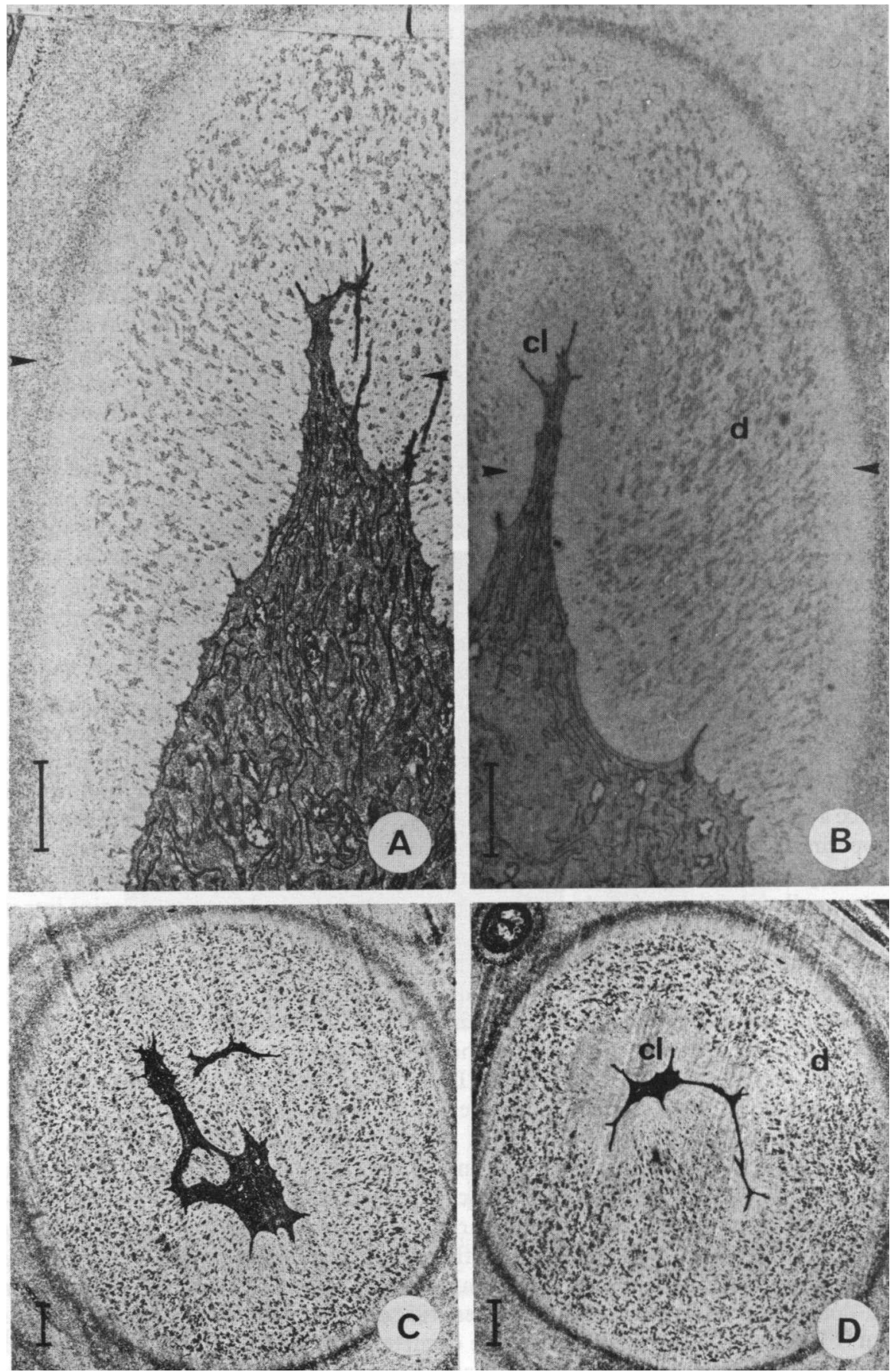

Plate 2. Physcia stellaris. A, C, Longitudinal and cross-sections of the ascus apex during dome (d) formation. The branchings of the cytoplasm are visible in the longitudinal as well as in the cross-section. B, D, Longitudinal and cross-sections of the nearly complete dome Around the ocular chamber the central layer $(\mathrm{cl})$ is visible. Fixation in potassium permanganate. 

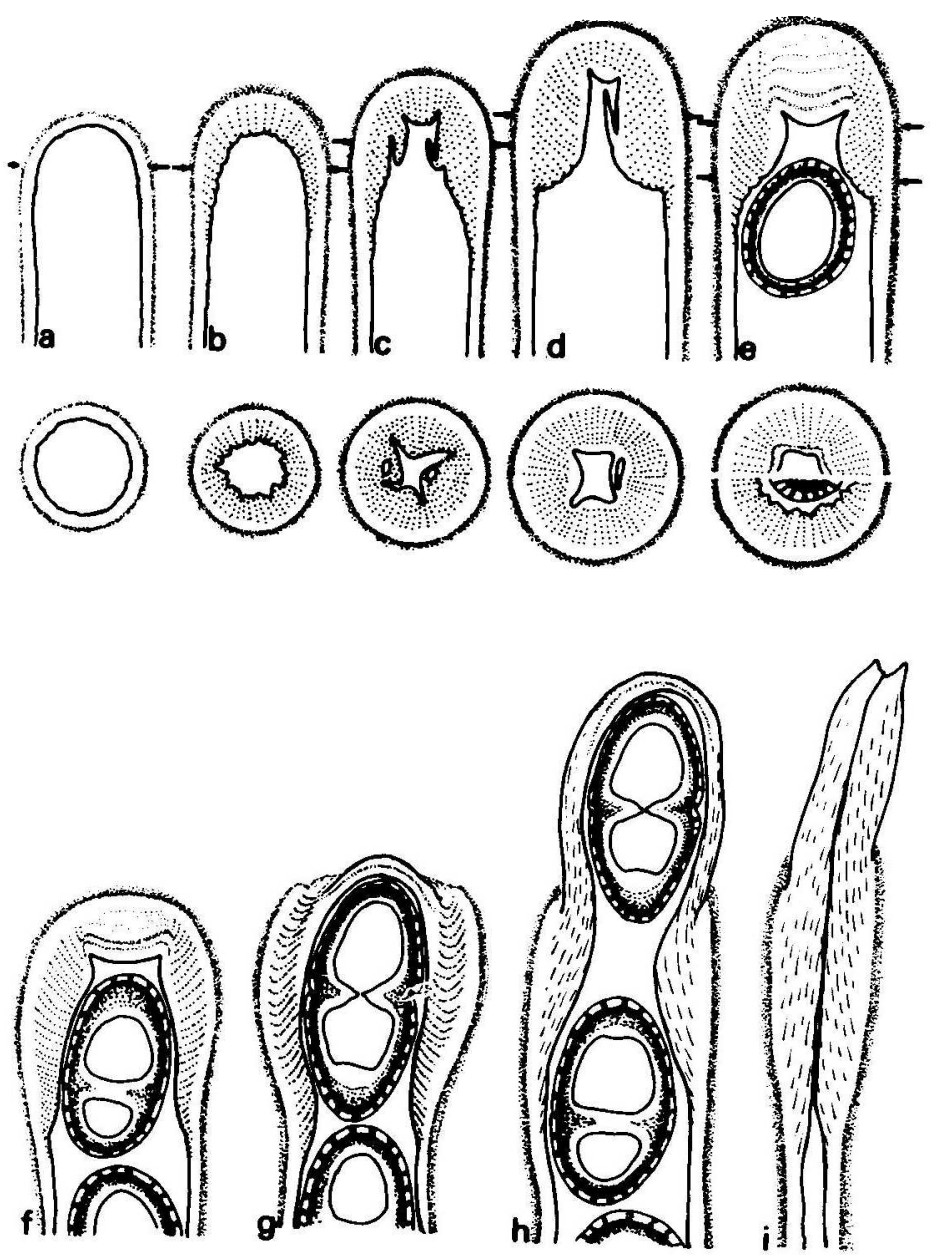

FIG. 2. Diagram of ascus development and function in Physcia stellaris according to the present TEM and LM observations. The arrows indicate the position of the cross-sections.

function of the apical apparatus. In a following period of higher humidity, paraphyses penetrate the ascus and ascospore wall and probably resorb a part of the cytoplasmic substances. In old apothecia, packets of completely shrunken ascospore walls can be found in the lowest part of the hymenium or even in the subhymenial layer.

\section{Conclusions}

The main components of the asci of the Lecanora-type are: (1) a non-amyloid electron-transparent ascus wall surrounded by an amyloid outer layer ('fuzzy coat'); (2) an amyloid dome containing electron-dense granular inclusions in an electron-transparent matrix; (3) an electron-transparent central layer of the dome; and (4) a rostrate method of dehiscence. 

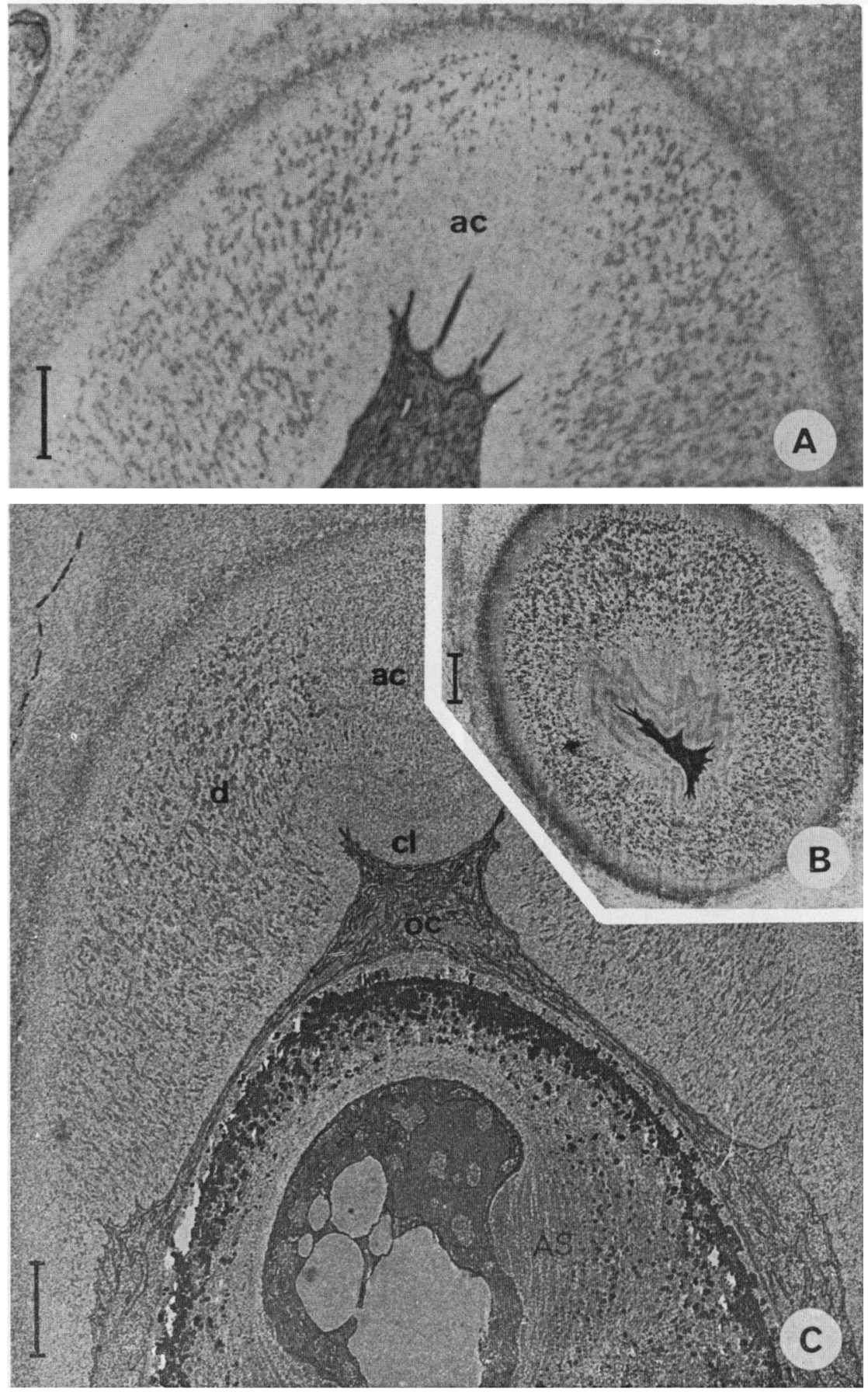

Plate 3. Physcia stellaris. A, Median longitudinal section of the ascus apex during ascospore maturation. In the zone of the apical cushion (ac) the electron-dense granular inclusions disappear. B-C, Median longitudinal (C) and cross-sections (B) of the mature ascus. In the apical cushion (ac) a fine, lamellate structure is seen. cl, central layer; d, dome; oc, ocular chamber. Fixation in potassium permanganate. 

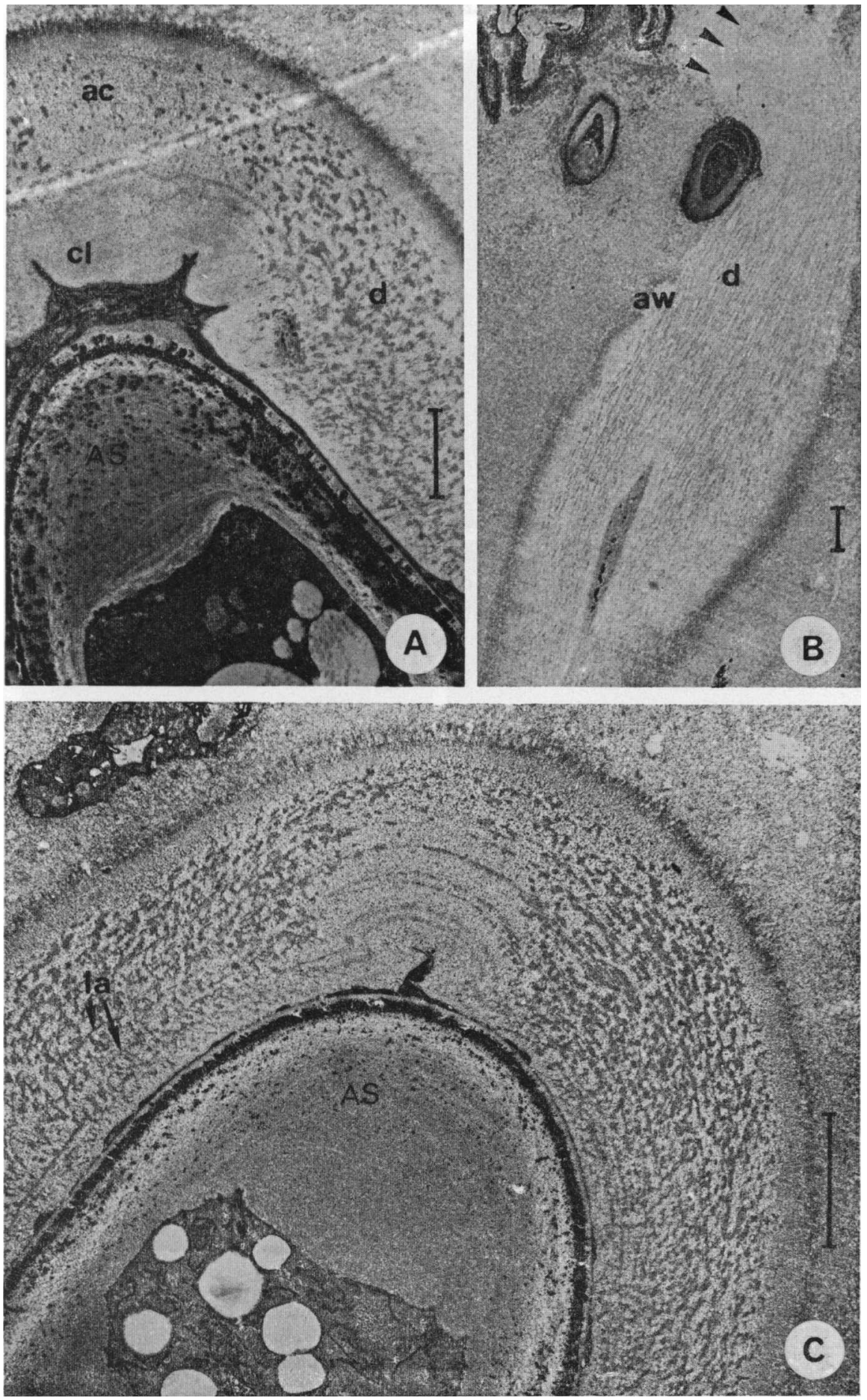

Plate 4. Physcia stellaris. A, Median longitudinal section of the ascus apex just prior to dehiscence. The uppermost ascospore (AS) is pressed into the ocular chamber. B, Longitudinal section of the ascus after spore release. The rostrum reaches the hymenial surface (arrows). C, Ascus apex at the beginning of degeneration. A fine, lamellate structure due to the confluence of the granular electron-dense inclusions (la) can be observed. Fixation in potassium permanganate. 
The Lecanora-type was also found to occur in other species belonging to different families of the suborder Lecanorineae as circumscribed by Henssen and Jahns (1973) (Honegger, 1976). Variations in the width of the ocular chamber, in the distribution of the electron-dense inclusions over the dome, and in the size and shape of the dome (and therefore in the length of the rostrum) were observed.

The Lecanora-type is consequently unitunicate in the sense of Luttrell (1951). It is conceivable that the Lecanora-type could have evolved from a bitunicate ancestral form with a weak 'Jack in the box' mechanism by a reduction of the expansible endoascus to an apical dome. This is discussed further below.

\section{Peltigera-type}

(Corresponding to the 'type post-archaeascé' of Letrouit-Galinou, 1973)

The asci of Peltigera are of particular interest because of the presence of a strongly amyloid ring in the thickened ascus apex; this ring has previously been described by several authors (Ziegenspeck, 1926; Magne, 1946; Galinou, 1955; Chadefaud et al., 1963, 1969; Richardson, 1970; Letrouit-Galinou and Lallemant, 1971; Chadefaud, 1973; Letrouit-Galinou, 1973; Henssen and Jahns, 1973; Keuck, 1977) but its function remained obscure. Some authors have observed the formation of a rostrum prior to spore release; Letrouit-Galinou (1973) even reported an apical nasse swinging from the tip of the rostrum.

The ascus of Peltigera canina was investigated in this study.
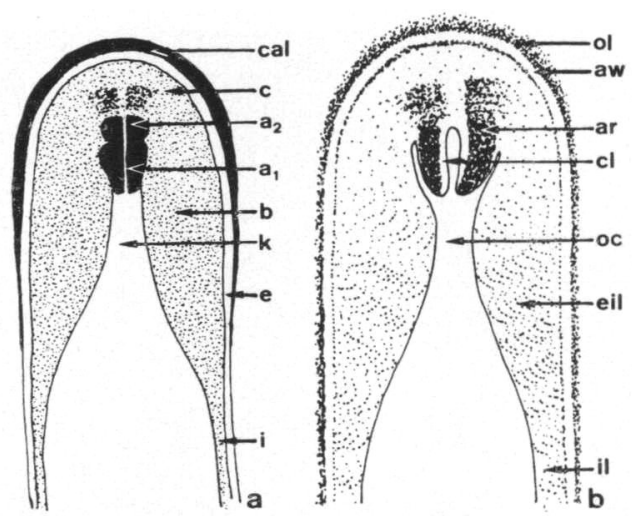

FIG. 3. Diagrammatic interpretations of the Peltigera-type ascus apex. (a) According to Magne (1946). (b) According to TEM micrographs.

$a_{1}, a_{2}$, deux anneaux amyloides; $b$, bourrelet sous-apical; cal, calotte apicale externe cuticulaire, amyloide; $e$, tunique externe ou cuticule de l'asque; $i$, tunique interne; $k$, chambre sousapicale; ar, apical ring; aw, ascus wall; $\mathrm{cl}$, central layer; eil, expansible inner layer; il, inner layer; oc, ocular chamber; ol, outer layer of ascus wall.

\section{Light microscopy}

The non-amyloid, rather thin-walled ascus is surrounded by a strongly amyloid and apically somewhat thickened outer layer. Very slightly amyloid material is deposited on the inner side of the whole ascus wall and it is this material which forms the apical thickening which contains a strongly amyloid ring (Plate 5C). The 

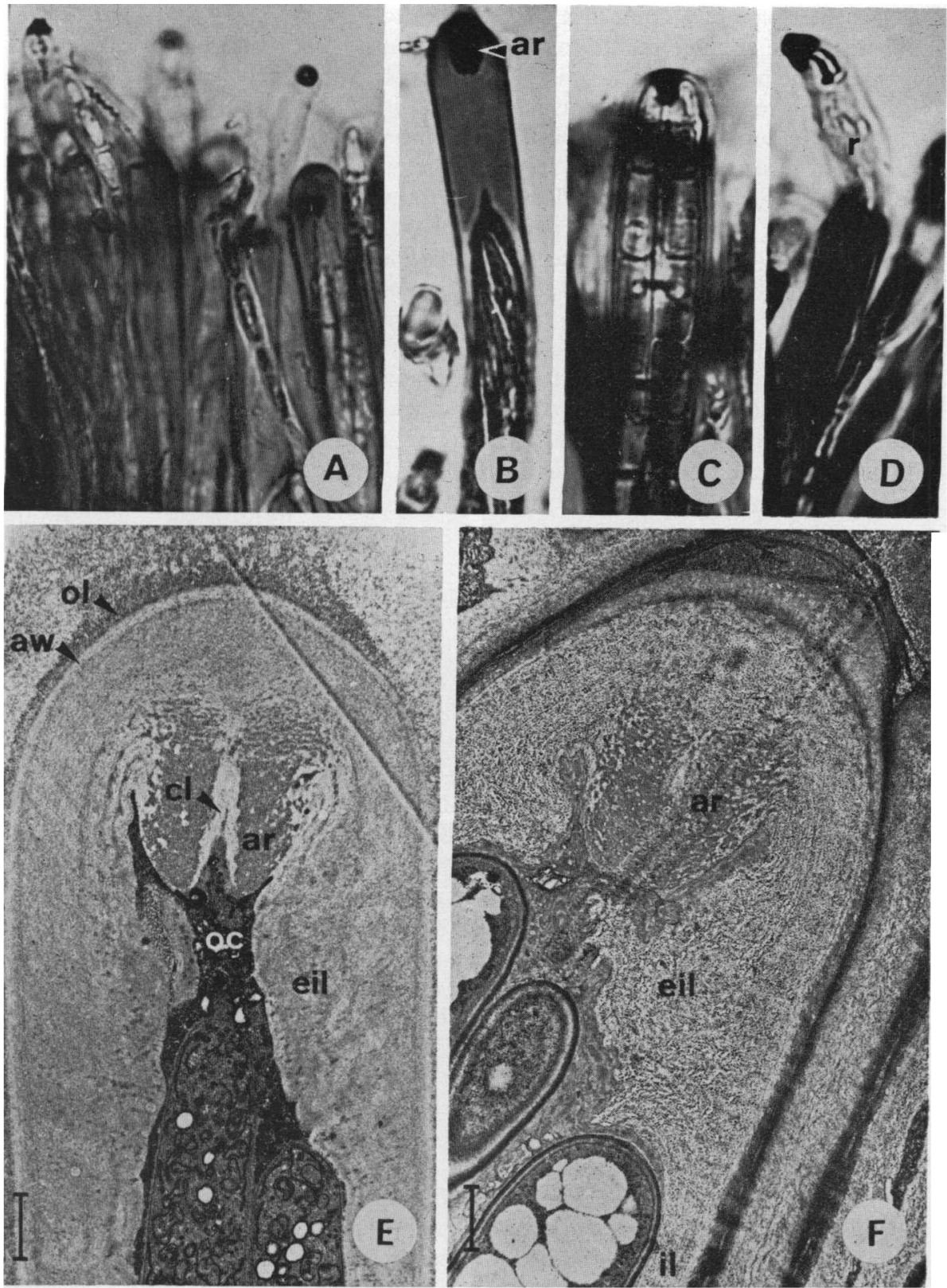

Plate 5. Peltigera canina. A-D, LM observations after staining with Lugol's solution. A, Part of the hymenium. B, Young ascus with the amyloid ring. C, During dehiscence. The ascus wall and its outer layer have ruptured, the apically thickened material of the inner layer, with the ring at its tip, expands to form the rostrum. D, After spore release. The amyloid ring at the tip of the rostrum (r) is everted. E, Median longitudinal section of the ascus at the beginning of ascospore formation. Fixation in potassium permanganate. $F$, Longitudinal, slightly tangential, section of the ascus apex. The 'accordion-structure' of the expansible inner layer is of particular interest. Fixation in glutaraldehyde and acrolein/ osmium tetroxide. 
ring has the shape of a truncated cone whose thicker end is directed towards the apex, while the thinner points towards the base of the ascus. During ascospore maturation the material of the apical thickening becomes increasingly compressed. Prior to spore release the apical ascus wall and its outer layer burst, and then the slightly amyloid material of the apical thickening with the amyloid ring at the tip is stretched to form a long rostrum reaching above the hymenial surface (Plate $5 \mathrm{C}$ ). The ring then becomes everted (Plate 5D) and the spores are released. Many of the empty asci seem no longer to have a ring at the tip of their rostrum; this is presumed to have broken off during or after spore discharge. This phenomenon was also observed in Xylaria longipes (Beckett and Crawford, 1973). The particular amyloid ring around the septal pore at the base of an ascus of Peltigera canina observed by Magne (1946) and cited by Chadefaud (1973) in support of his hypothesis on the analogy of annular structures in the apical region of the asci and the septal pores, was probably an apical ring broken off during preparation (squashing?) and accidentally positioned exactly at the base of an ascus.

It may be of interest to note that the fruiting bodies of various Peltigera species contain a nonamyloid hymenial gelatine.

\section{Electron microscopy}

In TEM the amyloid ring is visible after fixation with potassium permanganate as well as with aldehydes and osmium tetroxide as an electron-dense structure. Inside the ring a thin, electron-transparent layer is seen which possibly corresponds to the central layer described in the Lecanora-type. The material deposited inside the primary ascus wall is of particular interest: an inner layer is deposited in the whole ascus, but in the apical region this inner layer forms a conspicuous thickening. With the exception of very few electron-dense granular inclusions, almost no structures are seen in this apical thickening after fixation with potassium permanganate (Plate 5E), but after aldehyde/osmium tetroxide-fixation (Plate 5F; Plate 6A) the inner layer shows, at least in the apical region, the striated 'accordionstructure' characteristic of the bitunicate type (Reynolds, 1971; Bellemère, 1971; Griffiths, in Beckett et al., 1974). This 'accordion-structured' material of the apical thickening becomes elongated into a long rostrum during dehiscence and is termed the extensible inner layer; this corresponds to the 'endoascus' of Luttrell (1951). A gliding between the ascus wall and the extensible inner layer then occurs (Plate 7A-B). The eversion of the amyloid ring noted by LM was not observed in TEM but the everted ring probably recalls that of Xylaria longipes (Beckett and Crawford, 1973).

\section{Conclusions}

The ascus of the Peltigera-type differs fundamentally from the Lecanora-type. Whereas the Lecanora-type is unitunicate, the Peltigera-type is an interesting variant of the bitunicate type opening by a slight 'Jack in the box'. A similar type, but without an amyloid ring, has been found in Nephroma (Ziegenspeck, 1926; LetrouitGalinou and Lallemant, 1970). The peculiarity of the Peltigera-type is its amyloid ring, and because of this it has been an object for phylogenetic and evolutionary speculation.

The Peltigera-type was interpreted by Magne (1946) as an ancestral form of the Lecanora-type, while Letrouit-Galinou (1973) suggested it was descended from 

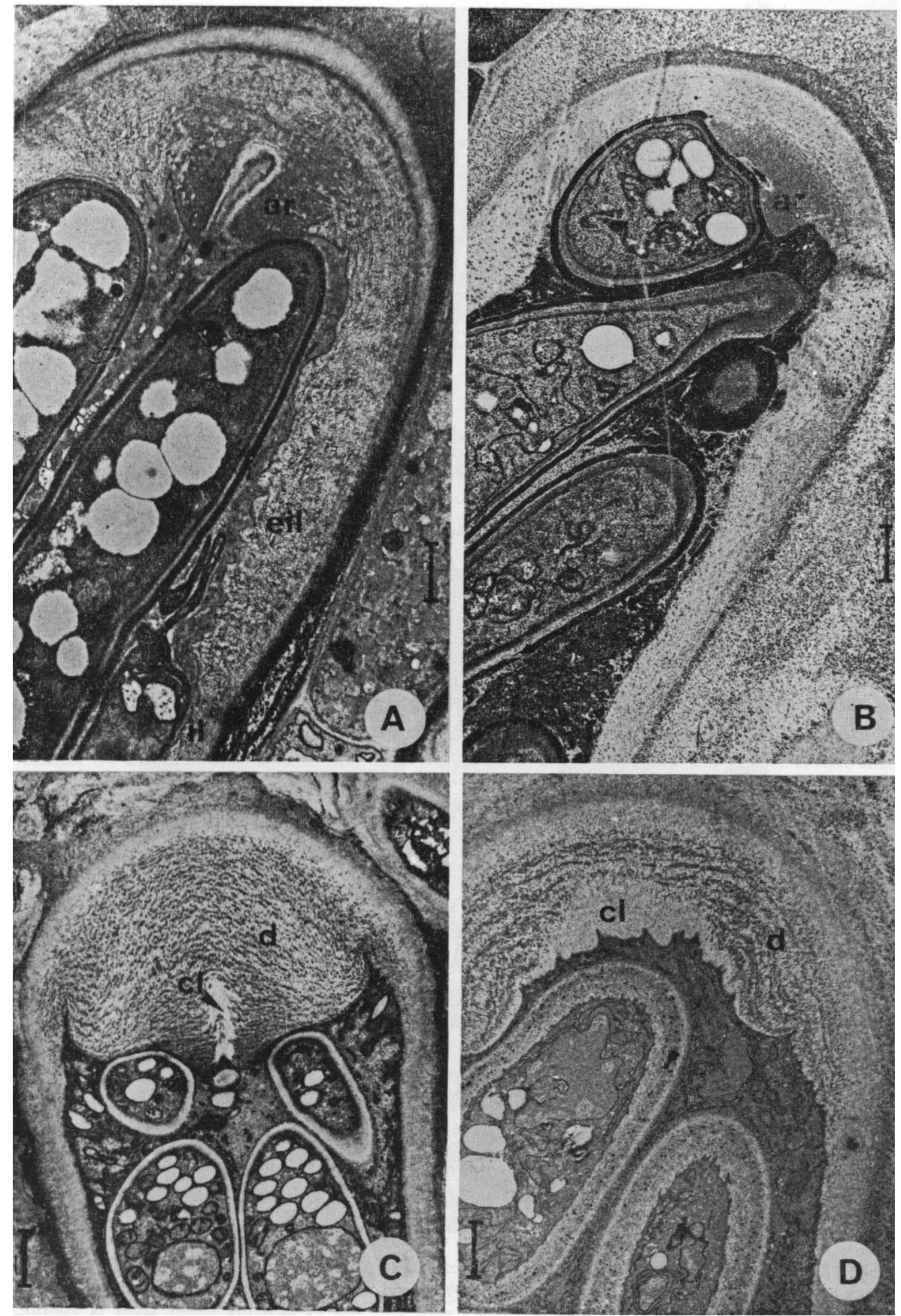

Plate 6. Peltigera canina. A, Median longitudinal section of an almost mature ascus. The expansible inner layer is somewhat compressed. Fixation in glutaraldehyde and acrolein/ osmium tetroxide. B, Longitudinal section of the mature ascus prior to dehiscence. Fixation in potassium permanganate. C-D, Two variants of the unitunicate Lecanora-type, both fixed with potassium permanganate. $\mathrm{C}$, Median longitudinal section of the ascus of Cladonia macilenta. D, Median longitudinal section of the ascus apex of Buellia stellulata. 

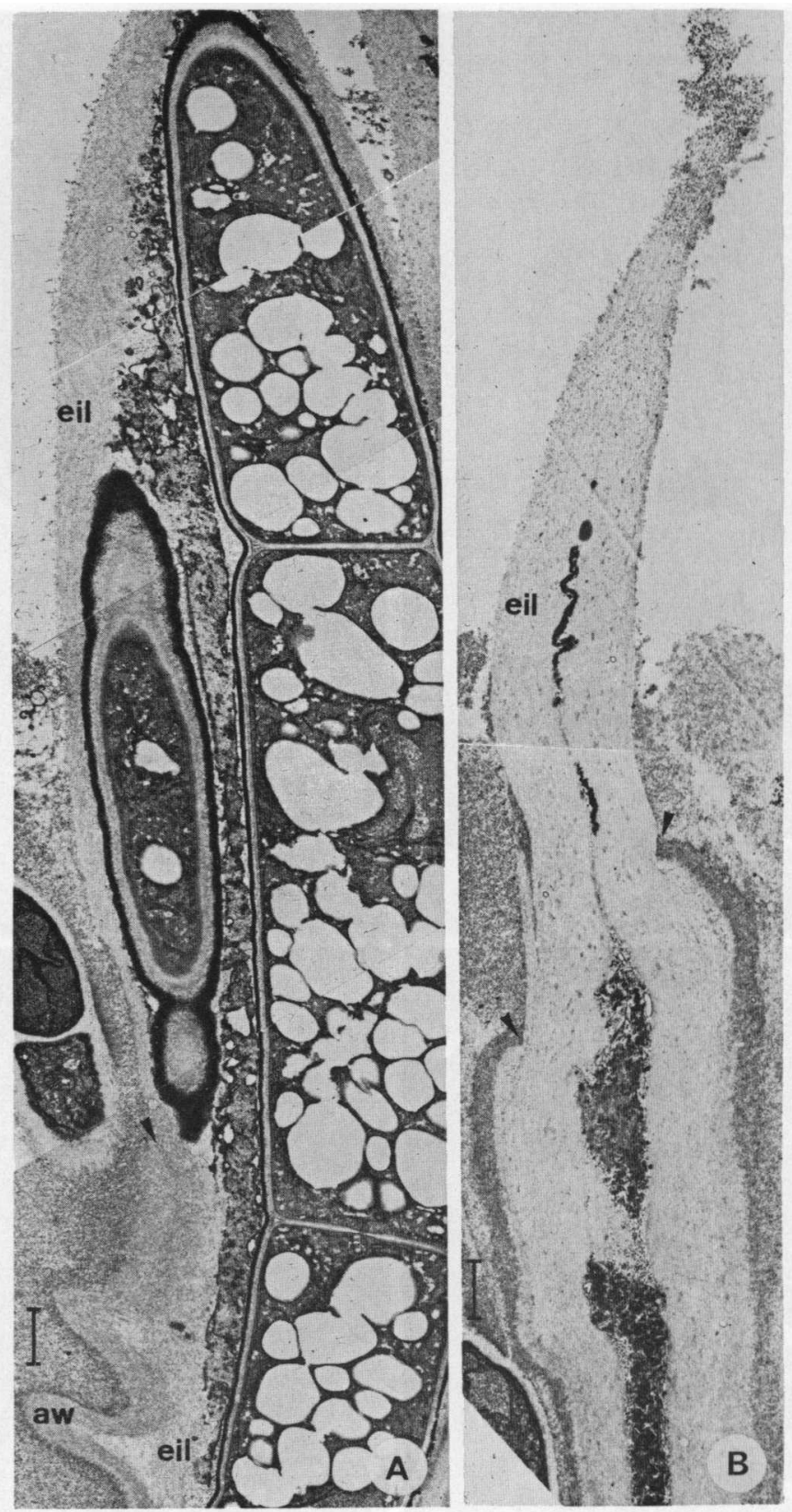

Plate 7, Peltigera canina. A, Longitudinal section of the ascus prior to spore release. The ascus wall and its outer layer have ruptured, the expansible inner layer (eil) is stretched to a rostrum. The gliding site between the ascus wall and the expansible inner layer is visible. B, Longitudinal section of the empty ascus. The long, somewhat curved rostrum is tangentially sectioned. Fixation in potassium permanganate. 

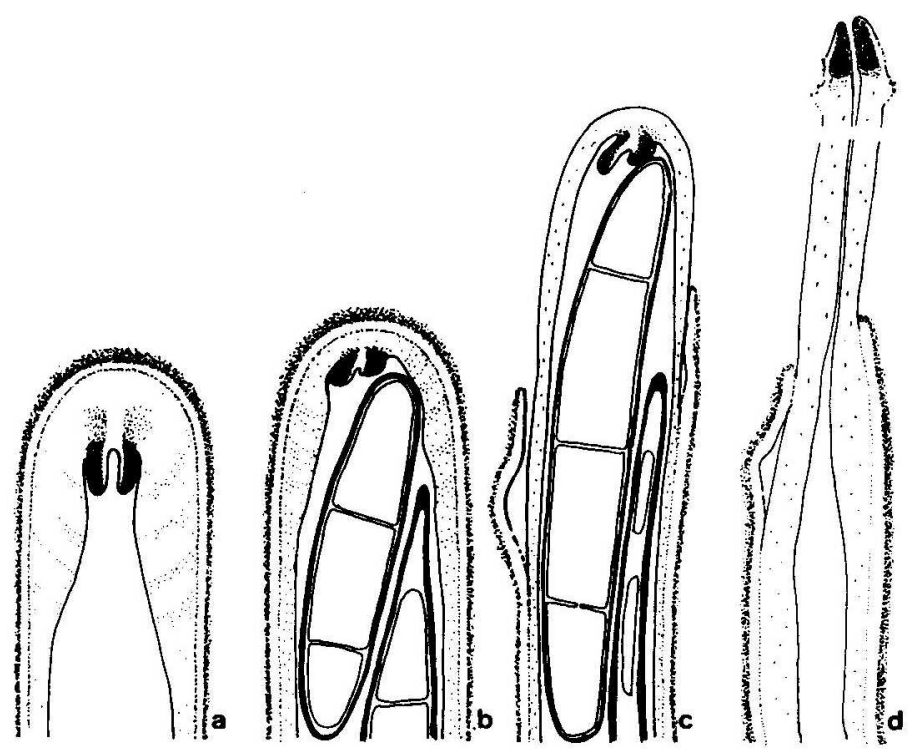

FIG. 4. Diagram of ascus function in Peltigera canina according to TEM and LM observations. Fig. $4 \mathrm{~d}$ is reconstructed according to LM observations and micrographs of Xylaria longipes (Beckett and Crawford, 1973).

the Lecanora-type linking the Lecanora- with the pyrenomycete-type ('type annellascé'). It is conceivable that the Lecanora-type has evolved from a similar form as the Peltigera-type by a reduction of the extensible inner layer to an apical dome, by a dispersion of the amyloid material of the ring over the whole dome and by an enlargement of the ocular chamber. The ascus of Cladonia (e.g. Cl. macilenta, Plate $6 \mathrm{C}$ ) seems to be a variant of the unitunicate Lecanora-type which may provide a linkage back to forms recalling the Peltigera-type. The ascus of Buellia (e.g. $B$. stellulata, Plate 6D), a further variant of the Lecanora-type, could be interpreted as intermediate between the Cladonia- and Physcia-variants because of the enlarged ocular chamber and the somewhat unequal dispersion of the electron-dense granular inclusions over the dome.

Peltigera is consequently a further example of an ascohymenial fungus with bitunicate asci (the ascocarp development has been studied by Letrouit-Galinou and Lallemant, 1971). This same situation has been described in many other lichenized and non-lichenized fungi which seem to be especially interesting and worthy of further investigations (Butler, 1939, 1940; Santesson, 1949, 1953; Müller, 1954; Pantidou and Korf, 1954; Groenhardt, 1962; Müller and von Arx, 1962; Richardson and Morgan-Jones, 1964; Parguey-Leduc, 1966, 1967; Pirozynski and Reid, 1966; Muthappa, 1967, 1970; Letrouit-Galinou and Lallemant, 1970; Bellemère, 1971; Henssen and Jahns, 1973; von Arx and Müller, 1975; Hafellner and Poelt, 1976).

\section{Teloschistes-type}

(Corresponds to the 'type pré-archaeascé' of Letrouit-Galinou, 1973)

The asci of different species of the suborder Teloschistineae were studied by Magne (1946), Chadefaud (1969, 1973), Richardson (1970), Letrouit-Galinou 
(1973) and Henssen and Jahns (1973). All these authors observed a strongly amyloid, cap-like zone at the ascus apex. The mode of dehiscence was described by Richardson (1970) who noticed the 'eversion of an inner collar' prior to spore release, and by Letrouit-Galinou (1973) who observed a bursting of the ascus with a longitudinal split prior to spore release ('dehiscence bivalve').

The ascus of Xanthoria parietina was investigated as a representative of the Teloschistes-type.

\section{Light microscopy}

The non-amyloid ascus wall is surrounded by an apically thickened amyloid outer layer. The apical dome consists of a non-amyloid inner and a strongly amyloid outer part, both of about the same thickness. Dehiscence occurs by a longitudinal split (Plate 8A) but it is difficult to interpret the structure and function of this ascus type in LM (see Fig. 5). No sharp delimitations between different zones of the ascus apex were discernible.
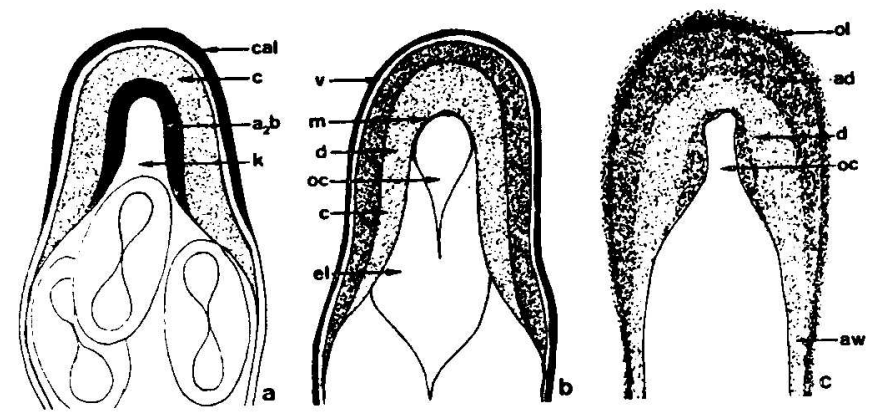

FIG. 5. Diagrammatic interpretations of the Teloschistes-type ascus apex. (a) According to , Magne (1946). (b) According to Chadefaud (1969). (c) According to TEM studies of Xanthoria parietina.

$a_{2} b$, complexe amyloide englobant l'anneau superieur et le bourrelet sous-apical; $c$, coussinet sous-apical; cal, calotte apicale externe cuticulaire, amyloide; $k$, chambre sous-apical

c, deux coupules épiloculaires emboîtées; d, dôme apical; el, masse intra-loculaire faiblement chitinoide; $m$, ménisque; oc, chambre oculaire; $v$, vagina.

ad, amyloid part of the dome; aw, ascus wall; $d$, dome; oc, ocular chamber; ol, outer layer of the ascus wall.

\section{Electron microscopy}

In extremely young asci the ascus wall is surrounded by an apically thickened 'fuzzy coat' (Plate 8B). Subsequently, wall material is deposited over the whole inner surface of the ascus wall; this deposition is very limited in the lateral and basal parts of the asci but increased considerably at the apex to form the thick dome. A peculiarity of the Teloschistes-type appears to be that the outer part of the dome becomes electron-dense (potassium permanganate-fixation) in about the same proportion as electron-transparent material is deposited around the ocular chamber (Plate 8C). The electron-dense part of the dome corresponds to the amyloid, cap-like 

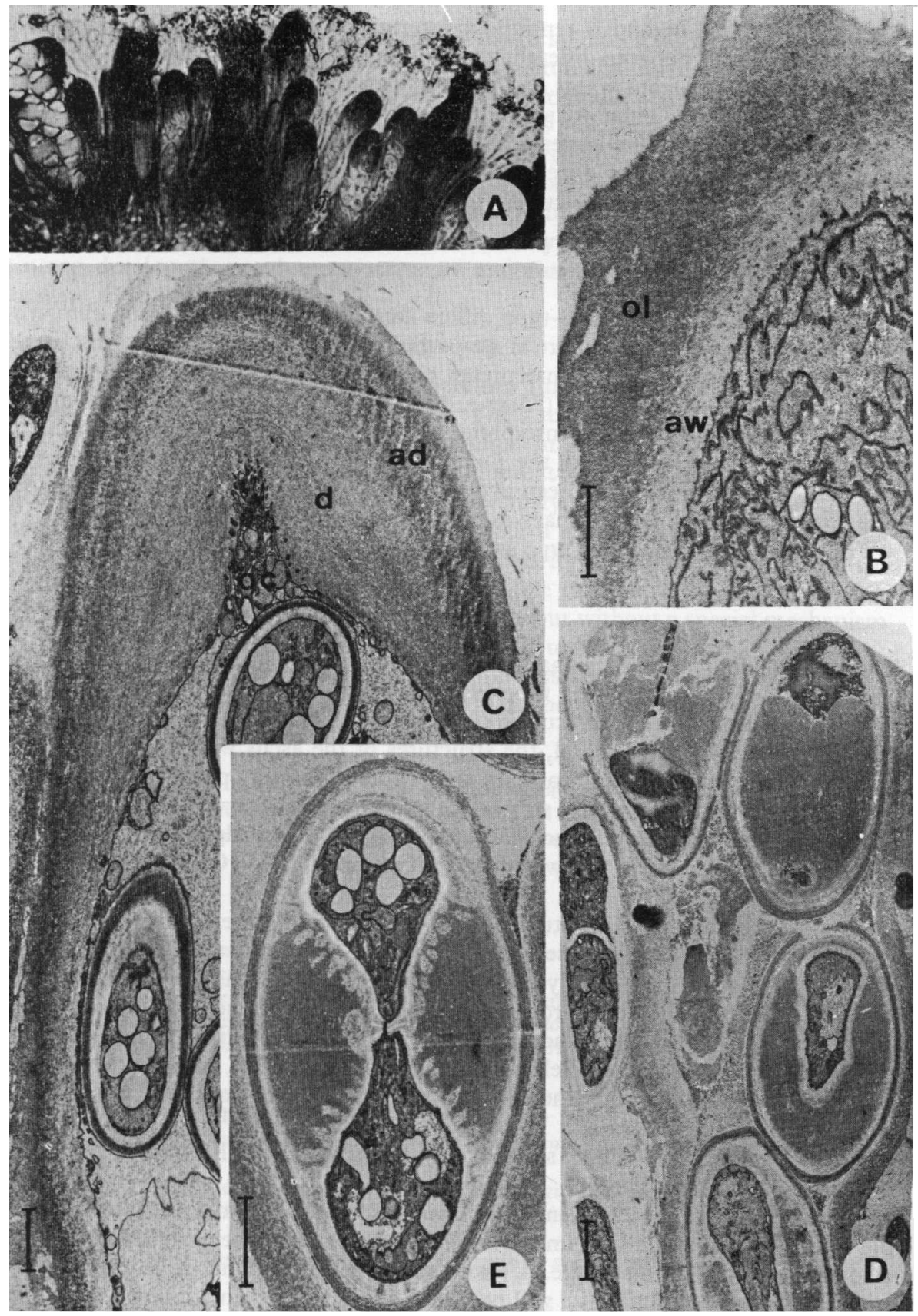

PLATE 8. Xanthoria parietina. A, LM observation of the hymenium after staining with Lugol. B, Median longitudinal section of a young ascus apex. C, Median longitudinal section of a mature ascus. D, Longitudinal section of an ascus during spore release. E, Median longitudinal section of a mature ascospore. Fixation in potassium permanganate. ad, amyloid part of the dome; $d$, non-amyloid part of the dome. 
zone observed in LM and is tentatively interpreted as an amorphous region. No sharp delimitations between different zones of the ascus apex are visible in TEM.

Both the electron-transparent and electron-dense materials of the dome seem to be somewhat elastic. Prior to spore release the material of the dome becomes slightly stretched by the uppermost ascospores being pressed into the ocular chamber. No separation of different parts of the wall or the dome occurs during dehiscence (Plate 8D). The factors triggering the splitting and spore release are unknown.

\section{Conclusions}

The ascus of the Teloschistes-type differs considerably from both the Peltigeraand the Lecanora-types. As there is no particular mechanism for spore discharge, the Teloschistes-type could be interpreted either as a primitive (Letrouit-Galinou, 1973) or reduced modification (Magne, 1946) of the Lecanora-type. The micrographs, however, allow a third interpretation; it is conceivable that the Teloschistestype is not as closely related to the Lecanora-type as has been generally supposed but could, for example, have been evolved from an unknown bitunicate ancestral type by a reduction of the primary ascus wall to a thick 'fuzzy coat'.

The asci of the Teloschistes-type are functionally unitunicate.

\section{Discussion}

The present study indicates that TEM investigations are valuable in the interpretation of the structure and function of different ascus types in the lichenized fungi. It did not prove too difficult to correlate the structures observed by LM with those seen in TEM. In general, the structures of the ascus wall, and above all of the apical apparatus, are less complex than some previously published interpretations of LM investigations have suggested; a comparable observation has been made by different authors studying non-lichenized fungi (Greenhalgh and Evans, 1967; Reeves, 1971; Beckett and Crawford, 1973; Campbell, 1973; Griffiths, 1973; Hohl and Streit, 1975).

From the comparative LM studies of the ascus apex of different lichenized fungi so far carried out, it can be seen that its apical structures remain more or less constant within the same family but vary between families. As far as the structure of the asci is concerned, the order Lecanorales (sensu Henssen and Jahns, 1973), containing 22 families, is rather heterogeneous. The sub-division into six suborders (e.g. Lecanorineae, Peltigerineae, Teloschistineae), based primarily on ascocarp ontogeny, is also found to be supported by ascus structure and function with a single exception: the Physciineae should perhaps be united with the Lecanorineae. Further TEM studies may be expected to lead to further subdivisions of the Lecanorineae.

For taxonomic purposes it is not only important to describe different structures in the ascus, but above all to understand the function of these structures during dehiscence and spore discharge. A knowledge of the functional significance of the various components of the asci will help to avoid an over-evaluation of some structures observed in LM or TEM.

At present little can be said about the phylogenetic position of the Lecanorales in general, and the species studied in this paper in particular, on the basis of ascus 
structure. As long as it is impossible to envisage an ancestral lichenized fungus, all such suggestions must remain hypothetical. Bitunicate forms with slight 'Jack in the box' dehiscence and discothecia (e.g. some Arthoniales and some Dothiorales) have been considered primitive (Santesson, 1949; Bellemère, 1971). If this is accepted the Peltigera-type asci could be regarded as more primitive than the unitunicate Lecanora-type. Because of their complex ascus structures and ascocarp development, it is tempting to interpret lichenized fungi with asci of the Lecanoratype as relatively evolved rather than archaic types. Further studies of both ascocarp development and ascus structure and function are urgently needed to elucidate these problems.

\section{Summary}

Three different ascus types in the lecanoralean fungi have been investigated by light and transmission electron microscopy. The Lecanora-type, the most common ascus type within the Lecanorales, was studied in Physcia stellaris: this is unitunicate and no gliding occurs between the different layers of the ascus wall or the apical apparatus during dehiscence. The Peltigera-type, studied in P. canina, is an interesting variant of the bitunicate type; there is a gliding site between the ascus wall and the expansible inner layer, and a pecularity of the Peltigera-type is an eversible amyloid ring at the tip of the expansible inner layer. The Teloschistestype, studied in Xanthoria parietina, is unitunicate but without a special mechanism for spore discharge, just splitting at the apex prior to spore release.

The results obtained are compared with previous studies and the phylogenetic concepts of other workers. The thesis that the Lecanora-type is an evolved rather than an archaic form is supported.

I thank Professor Dr A. Henssen, Professor Dr H. R. Hohl and Professor Dr E. Müller for valuable discussions; Professor Dr R. Parish and Dr D. L. Hawksworth for reading and correcting the manuscript; and the Janggen-Poehn-Stiftung, St Gallen, for financial support.

\section{REFERENCES}

von Arx, J. A. and Müller, E. (1975) A re-evaluation of the bitunicate Ascomycetes with keys to families and genera. Stud. mycol., Baarn 9: 1-159.

Beckett, A. and Crawford, R. M. (1973) The development and fine structure of the ascus apex and its role during spore discharge in Xylaria longipes. New Phytol. 72: 357-369.

Beckett, A., Heath, I. B. and McLaughlin, D. J. (1974) An Atlas of Fungal Ultrastructure. London: Longman.

Bellemère, A. (1971) Les asques et les apothecies des Discomycètes bituniqués. Annls Sci. nat. (Bot.), sér. 12, 12: 429-464.

Butler, E. T. (1939) Ascus dehiscence in Lecanidion atratum and its significance. Mycologia 31 : $612-623$

Butler, E. T. (1940) Studies in the Patellariaceae. Mycologia 32: 791-823.

Campbell, R. (1973) Ultrastructure of asci, ascospores and spore release in Lophodermella sulcigena (Rostr.) v. Höhn. Protoplasma 78: 69-80.

Chadefaud, M. (1969) Remarques sur les parois, l'appareil apical et les reserves nutritives des asques. Ost. Bot. Z. 116: 181-202.

Chadefaud, M. (1973) Les asques et la systematique des Ascomycètes. Bull. trimest. Soc. mycol. Fr. 99 : 127-170.

Chadefaud, M., Letrouit-Galinou, M.-A. and Favre, M. C. (1963) Sur l'évolution des asques et du type archaeascé chez les discomycètes de l'ordre des Lecanorales. $C$. $r$. hebd. Séanc. Acad. Sci., Paris, sér. D, 257: 4003-4005. 
Chadefaud, M., Letrouit-Galinou, M.-A. and Janex-Favre, M. C. (1969) Sur l'origine phylogénétique et l'évolution des Ascomycètes des lichens. Bull. Soc. bot. Fr., Mém. 1968 (Coll. lich.): 79-111.

Dughi, R. (1957) Membrane ascale et revivischence chez les champignons licheniques discocarpes inoperculés. Annls Fac. Sci. Marseille 26: 3-20.

Galinou, M.-A. (1955) Le système apical des asques chez differentes espèces de lichens des genres Nephroma, Solorina, Peltigera. C. r. hebd. séanc. Acad. Sci., Paris, sér. D 241 : 99-101.

Greenhalgh, G. N. and Evans, L. V. (1967) The structure of the ascus apex in Hypoxylon fragiforme with reference to ascospore release in this and related species. Trans. $B r$. mycol. Soc. 50: 183-188.

Griffiths, H. B. (1973) Fine structure of seven unitunicate pyrenomycete asci. Trans, $\mathrm{Br}$. mycol. Soc. 60: 261-271.

Groenhardt, P. (1962) Aglaothecium Groenh., a new lichen from Malaysia. Persoonia 2: 349-353.

Hafellner, J. and Poelt, J. (1976) Die Gattung Karschia-Bindeglied zwischen bitunicaten Ascomyceten und lecanoralen Flechtenpilzen? Pl. Syst. Evol. 126 : 243-254.

Henssen, A. and Jahns, H. M. (1973) ['1974'] Lichenes. Eine Einführung in die Flechtenkunde. Stuttgart: Thieme.

Hohl, H. R. and Streit, W. (1975) Ultrastructure of ascus, ascospore and ascocarp in Neurospora lineolata. Mycologia $67: 367-381$.

Honegger, R. (1976) Licht- und elektronenoptische Untersuchungen an Flechten-Asci vom Lecanora-typ. Dissertation, Universität Basel.

Keuck, G. (1977) Ontogenetisch-systematische Studie über Erioderma im Vergleich mit anderen cyanophilen Flechtengattungen. Biblthca lich., Lehre 6: 1-175.

Korf, R. B. (1958) Japanese Discomycete Notes I-VIII. Sci. Rep. Yokohama natn. Univ., sect. 2, 7: 7-35.

Kreisel, H. (1969) Grundzüge eines natürlichen Systems der Pilze. Lehre: J. Cramer.

Letrouit-Galinou, M.-A. (1970) Les apothécies et les asques du Parmelia conspersa. Bryologist 73: 39-58.

Letrouit-Galinou, M.-A. (1973) Les asques des lichens et le type archaeascé. Bryologist $76: 30-47$.

Letrouit-Galinou, M.-A. and Lallemant, R. (1970) Le developpement des apothécies du Nephroma resupinatum (L.) Ach. Revue gén. Bot. 77: 331-351.

Letrouit-Galinou, M.-A. and Lallemant, R. (1971) Le thalle, les apothécies et les asques du Peltigera rufescens (Weis.) Humb. Lichenologist 5: 59-88.

Luttrell, E. S. (1951) Taxonomy of the pyrenomycetes. Univ. Mont. Stud. 24 (3): 1-120.

Magne, F. (1946) Anatomie et morphologie comparées des asques de quelques lichens. Revue bryol. lichén. 15: 203-209.

Müller, E. (1954) Des discomycètes bituniqués. 8e Congr. Int. Bot., Rapports et Comm., sect. 19: 51-53. Paris.

Müller, E. and von Arx, J. A. (1962) Die Gattungen der didymosporen Pyrenomyceten. Beitr. KryptogFlora Schweiz 11 (2): 1-922.

Müller, E. and Löfler, W. (1968) Mycologie. Stuttgart: Thieme.

Muthappa, B. N. (1967) Tryblidiella rufula on diverse substrata and its taxonomic position. Nova Hedwigia 14: 395-401.

Muthappa, B. N. (1970) Morphology of Tryblidiella clavispora. Mycologia 62: 98-106.

Pantidou, M. E. and Korf, R. B. (1954) A revision of the genus Keithia. Mycologia 46: 386-387.

Parguey-Leduc, A. (1966) Recherche sur l'ontogénie et l'anatomie comparée des ascocarpes des Pyrenomycètes ascoloculaires. Annls Sci. nat. (Bot.), sér. 12, 7: 505-690; 8: 1-103.

Parguey-Leduc, A. (1967) Recherches préliminaires sur l'ontogénie et l'anatomie comparée des ascocarpes des Pyrenomycètes ascohymeniaux. I. Notions générales. Revue mycol. 32 : $57-68$.

Pirozynski, K. A. and Reid, J. (1966) Studies on the Patellariaceae. 1. Eutryblidiella sabinae. Can. F. Bot. 44: 655-661.

Reeves, F. B. (1971) The structure of the ascus apex in Sordaria fimicola. Mycologia 63: 204-212.

Reynolds, D. R. (1971) Wall structure of a bitunicate ascus. Planta 98: 244-257. 
Richardson, D. H. S. (1970) Ascus and ascocarp structure in lichens. Lichenologist 4 : 350-361.

Richardson, D. H. S. and Morgan-Jones, G. (1964) Studies on lichen asci I. The bitunicate type. Lichenologist 2: 205-224.

Rudolph, E. D. and Giesy, R. M. (1968) EM-studies of lichen reproductive structures in Physcia aipolia. Mycologia 58: 786-796.

Santesson, R. (1949) Dolichocarpus and Xanthopeltis, two new lichen genera from Chile. Svensk Bot. Tidskr. 43: 547-565.

Santesson, R. (1953) The new systematics of lichenized fungi. In Proceedings of the Seventh International Botanical Congress, Stockholm, 1950 (H. Osvald and E. Åberg, eds): 809-810. Stockholm: Almquist \& Wiksell.

Ziegenspeck, H. (1926) Schleudermechanismen von Ascomyceten. Bot. Arch. 13: 341-381.

Accepted for publication 11 November 1977 
Downloaded from https:/www.cambridge.org/core. University of Basel Library, on 11 Jul 2017 at 09:03:34, subject to the Cambridge Core terms of use, available at https:/www.cambridge.org/core/terms. https://doi.org/10.1017/S0024282978000079 